\title{
Modelling of water quality management in the sea coastal zone
}

\author{
Y.I. Dreizis ${ }^{1 . *}$ \\ ${ }^{1}$ Sochi State University, 94/1, Plastunskaya str., Sochi, 354000, Russia
}

\begin{abstract}
Coastal territories are one of the most dynamically developing regions. Sea resorts focused on recreational and tourist activities are developing especially quickly. For such territories, their ecological status, especially the quality of coastal zone water resources, plays an important role in their sustainable development. Analysis of physical factors of water exchange and assessment of water resources quality of the coastal zone of the sea, including in closed and semi-enclosed water areas, was carried out. It has been shown that water exchange is the most important factor in the management of the quality of marine waters of partially enclosed coastal areas. 0-dimensional and system-dynamic models were used to analyze water exchange in the coastal zone of the sea. Results of studies made it possible to assess the circulation of coastal marine waters and the change in certain indicators of the quality of water resources, including in the presence of various coastal protection construction.
\end{abstract}

\section{Introduction}

Sea water is the most important natural resource of the coastal zone of sea tourist regions used in recreational activities.

Coastal zone resource management is a complex issue. The coastal zone is an area of interaction between various processes: economic, natural and anthropogenic. And these processes often lead to conflicts in directions that relate to the use of resources of the sea coastal zone. Most coastal ecosystems and human activities in the coastal zone are associated with the use of coastal waters.

The traditional approach, called Integrated Coastal Zone Management (ICZM), is based on meeting the needs of consumers while preserving and protecting natural ecosystems. ICZM can offer a principled approach and some basic management principles that take into account the complex nature of the coastal zone. Under this approach, users of onshore resources are motivated to implement sustainable consumption only by the need to pay environmental payments, as compensation for environmental damage.

International environmental management standards, such as ISO 14000 /Environmental Management, 1999/ et al., have been actively implemented in the management of natural resources in recent years. They are also accepted as official Russian standards $[1,2]$ and have been further developed. These standards define the internal environmental

\footnotetext{
*Corresponding author: Yurid2006@yandex.ru
} 
management system. An important part of ISO 14000 is the damage-oriented life cycle assessment method "The Eco-indicator 99 (EI 99)" [3-5]. The use of this method is also recommended for coastal zone conditions, including damage assessment to water resources [4].

The coastal zone of the sea is significantly and constantly polluted by anthropogenic activities. Various contaminants lead to an increase in the mass of algae near the shore, reduce the concentration of oxygen dissolved in the water, especially near the coast, used for recreational and tourist purposes.

The tendency to increase the anthropogenic load on the coastal zone of the sea is pronounce in the modern world. This is due to a number of objective reasons, but the main one is the growth of the population in coastal zones, the growth of tourist flows on the coast and, as a result, the increase in environmental pollution. The specificity of the problem is to increase the recreational load on the coastal zone. The peak use of coastal waters for recreation and tourism falls on the most difficult period of water ecosystem functioning (summer) and leads to her gradual destruction [7-12].

The problem is complicate by the fact that for the tasks of coastal protection and for the protection of natural or artificial beaches, the construction of coastal protection structures is everywhere practice. These structures include groins, cove-shaped shores, longitudinal breakwater, artificial beaches, piers, port moles, etc. [8]. The presence of these structures leads to the need to determine the water quality in closed and partially closed coastal aquatories. These include lagoons, small bays, ports and beaches with coastal structures. These are coastal zones in which water exchange with the open sea is difficult. The ecosystems in these areas of the coastal zone die under the increasing flow of pollution, which comes, firstly, with surface runoff and precipitation, secondly, introduced by recreants, and, thirdly, arising from technogenic accidents or disasters.

Water quality is characterize by the concentration of suspended substances. They largely determine the hydrochemical and hygienic state of the water of the coastal zone of the sea. There are good correlations between suspended matter concentrations and other water quality indicators. This allows the use of mathematical simulation models that determine the content of suspended substances, and then recalculate by the necessary (correlated) indicator of water quality [7-12].

The timely determination of pollution of natural waters by organic substances of anthropogenic origin responsible for reducing dissolved oxygen content is an extremely important task. The cause of bottom hypoxia is anthropogenic eutrophication of reservoirs. It causes disturbances in the functioning of aquatic ecosystems, which are manifest in a sharp increase in the development of phytoplankton, overgrowth of coastal shallow waters by aquatic vegetation and a change in the natural hydrochemical regime of water bodies. Analysis of the mesoscale variability of hydrological processes showed that in early to midsummer, the development of hypoxia could be significantly influence by the dynamic state of waters. First, these are longshore currents, shear turbulence, internal waves, wind and wave activity etc. [7-12].

Oxygen depression (with concentrations less than $2 \mathrm{ml} \mathrm{O} 21-1$ at the bottom occurs in the coastal zone of the coast in June-July. At the same time, hypoxia is most sharply manifested in estuary areas, coastal shallow waters and banks - in areas with characteristic hydrodynamic conditions where stagnation zones are formed [7-14].

\section{Materials and methods}

The purpose of the present study is to:

- analysis of physical factors of water exchange and assessment of the quality of coastal zone water resources in enclosed and semi-enclosed areas, 
- assessment of water exchange as an essential factor in the management of sea water quality in partially enclosed coastal areas.

0 -dimensional mathematical model was used to estimate water exchange in closed or semi-closed water areas. Model is based on estimating the propagation time of a conservative or non-conservative impurity under the influence of turbulent diffusion. This model was used to calculate water exchange. The modeling of substance flows is carried out using the PowerSim program, which is designed for system-dynamic modeling.

\section{Results and discussion}

\subsection{Physical water exchange factors for partially enclosed coastal areas}

To understand the problems encountered and to choose the best way to solve them, you must first know what are partially closed coastal waters, what processes are decisive for the normal development and functioning of the existing ecosystems there. The following criterion can be propose to determine the degree of closure of the water area [7-12]:

$$
\text { E.I. }=\frac{\sqrt{S_{a}} D_{p 1}}{W D_{p 2}}
$$

where E.I. - is the closure index, S - s the area of the limited part of the coastal zone, W - is the width of the inlet, Dp1 - is the average depth of the water area, Dp2 - is the average depth in the cross section of the inlet. If E.I. $>2$, the water area is closed, if $1<$ E.I. $<2-$ water area is partially closed, если E.I. $<2$ - water area is open.

Water quality may deteriorate in closed and partially closed sea areas for various reasons, for example, due to excessive plankton accumulation, which may lead to a decrease in oxygen content in the water area; due various contaminants introduced into the shore area by water users; due to technogenic accidents, etc. [8].

Three methods of controlling pollution of closed waters are known: control and limitation of pollution; clean-up activities; increased water exchange with open water area, if water exchange was artificially limited. Currently, there are opportunities to increase water exchange. For these purposes, firstly, it is possible to optimize the location of coastal protection structures to ensure better washing of the water area, and secondly, to use permeable breakwaters, groines and other types of permeable coastal protection structures.

Mathematical modeling of the process of pollution of closed coastal territories can be divide into two stages. The primary models initially examine the physical processes of coastal pollution spread as well as the related chemical and biochemical processes $[4,8$, 15]. Then, based on primary models, secondary models are constructed describing biological processes resulting from changes in pollutant concentration [7-9].

There are many features in the approach to the modelling of the pollution process related to the following circumstances:

- differences in density between seawater and effluents, leading to more complex forms of pollution;

- a wide range of ways in which pollutants can enter the area under study. These are, for example, surface drains (from shore to water surface), from the bottom (sea pipelines), from the side of a small vessel, with recreants;

- significantly greater diversity of ecosystems involved in water exchange [7-12]. In calm and light weather, the current system is determine mainly by coastal shallow flow. 


\subsection{Calculation of coastal seawater circulation based on 0 -dimensional models}

Estimates of water exchange in closed or semi-enclosed water areas can be based on 0dimensional models [7-10].

The degree of closing of territories in the coastal zone is determine by the parameter E.I. (Tab. 1) for coastal areas [7, 8].

Table 1. Parameter value E.I.

\begin{tabular}{|c|c|}
\hline Parameter value E.I. & Definition \\
\hline E.I. $>2$ & Closed water area \\
\hline $1<$ E.I. $<2$ & Semi-enclosed water area \\
\hline E.I. $<1$ & Open water area \\
\hline
\end{tabular}

Water exchange problems are associated with hydrometeorological factors and the configuration of the enclosed section of the water territory.

Calculations of water exchange can be based on estimates of the propagation time of various types of impurities, taking into account the influence of turbulent diffusion within the mathematical model. Calculation methodology and model for evaluation are present in works [7-10].

Modeling is a practical tool for predicting circulation for real water objects. At the same time, there is naturally a need for additional assessment of water exchange in the surf zone from flows induced by disruption of waves [7].

Environmental risk assessment contains not only technogenic risks, but also an assessment of the functioning of ecosystem elements in conditions of intense anthropogenic load. This load is characteristic of coastal tourist areas.

\subsection{Environmental damage to coastal zone water resources}

The water of the coastal zone of the sea can be consider as a recreational resource of the environment. Therefore, environmental damage should be analyze in the categories of damage. The accessibility of clean coastal waters is cover by categories of damage to the health of recreants and local populations, as well as ecosystems. The amount of coastal waters is not a limiting factor, but their quality is such for tourism and recreation. The quality of ecosystems is describe in the method EI-99 [3-5] through energy and substance flows. The degree of disruption of flows in the coastal ecosystem is an essential parameter for monitoring the quality of ecosystems.

Modelling of energy flows for coastal waters includes consideration of incoming energy flows essential for the coastal zone and their transformation. These flows are associated with waves, currents, rolling waves ashore, and dissipation of wave energy during their disruption, etc. The construction of coastal structures is an example of the violation of these flows because of anthropogenic activities, although they contribute to the preservation of seashores and beaches. The level of violations was consider in [8-10].

Modelling of substance flows can be carry out using PowerSim program designed for system-dynamic modeling, and the results can be used in assessing damage to ecosystems. Life cycle products that cause a temporary load on the aquatic ecosystem determine of its damage. Unlike his classical assessment (The Eco-indicator 99 1999), changes in water characteristics are not estimated [8-10]. 
Ecosystem damage caused by ecotoxic substances can be assess using EI 99 based on the calculation of toxic stress for the ecosystem [7-10]. To damage the aquatic ecosystems of the coastal zone of the sea, acidity growth and eutrophication are most important.

\subsection{Modelling effects on coastal water systems}

The increase in acidity and eutrophication is cause by accumulations of inorganic substances such as sulfates, nitrates and phosphates. These substances can enter water directly or penetrate from the atmosphere. They can also accumulate due to insufficient treatment of wastewater before it is discharge to sea or supplied by water outlets, rivers and sewage systems [7-10].

The problem was to determine what changes could be considered damage. The European version of EI 99 provides a list of species for 40 ecosystem types. This list represents the natural state of the ecosystem [3-5].

Damage can be modeling for the coastal ecosystem cell. If such a cell system is install, the accumulation effect can be modeling.

Results of the simulation of phytoplankton concentration on a limited sea aquatories using the PowerSim program are shown in figures below.

The main equation of the model in such calculations is the following equation $[8-10$, 16]:

$$
\frac{\partial n}{\partial t}=\frac{A_{z}}{\rho} \frac{\partial^{2} n}{\partial z^{2}}-v \frac{\partial n}{\partial z}+n(P-R)-H h n-q\left(n-n_{R}\right)
$$

where $\mathrm{n}$ - phytoplankton concentration, mg chlorophyll per $1 \mathrm{~m} 3, \mathrm{t}$ - time, Az coefficient of vertical turbulent diffusion, $\rho$ - density of water, $\mathrm{z}$ - vertical coordinate, $\mathrm{v}$ deposition rate, $\mathrm{P}$ - photosynthesis rate for unit concentration, $\mathrm{R}$ - breathing intensity for single concentration, $\mathrm{H}$ - concentration of zooplankton, $\mathrm{h}$ - the eating factor for a single concentration of zooplankton, $\mathrm{q}$ - the fraction of the volume of water changing per day due to water exchange with the environment, $\mathrm{nR}$ - the concentration of phytoplankton in the environment.

It is assume vertical diffusion is not significant compared to other transfer factors on the right side of equation (2). Therefore, the first term on the right (3) can be neglect. A twolayer depth model including surface and bottom layers [8-10] can be use to estimate the deposition rate. The photosynthesis rate is given by the simplified Smith equation [8-10]:

$$
P=b I P_{\text {opt }}
$$

where $\mathrm{I}$ is the intensity of solar radiation on the surface of the water, $\mathrm{b}$ is the coefficient. The optimal value of Popt is determined by the water temperature $T(C)$ :

$$
P_{\text {opt }}=\frac{3.1}{2} \exp (0.09 T)
$$

The modeling of phytoplankton growth in the aquatory with water exchange between this aquatory and the external aquatory of the sea using the program PowerSim is shown in Fig.1.

The simulation was carried out under the following initial conditions: water temperature of $22 \mathrm{C} 0$, water depth of $15 \mathrm{~m}$, phytoplankton deposition rate of $0.5 \mathrm{~m} /$ day, zooplankton concentration of $0.001 \mathrm{mg} / \mathrm{m} 3$, eating ratio for a single zooplankton concentration of 0.1 day-1 ( $\mathrm{mg} / \mathrm{m} 3)$. The system was simulate at two-water exchange intensities. The first was 0.01 days-1, which means a complete replacement of water in the region in 100 days. A simulation results is shown in Fig. 2-4. 


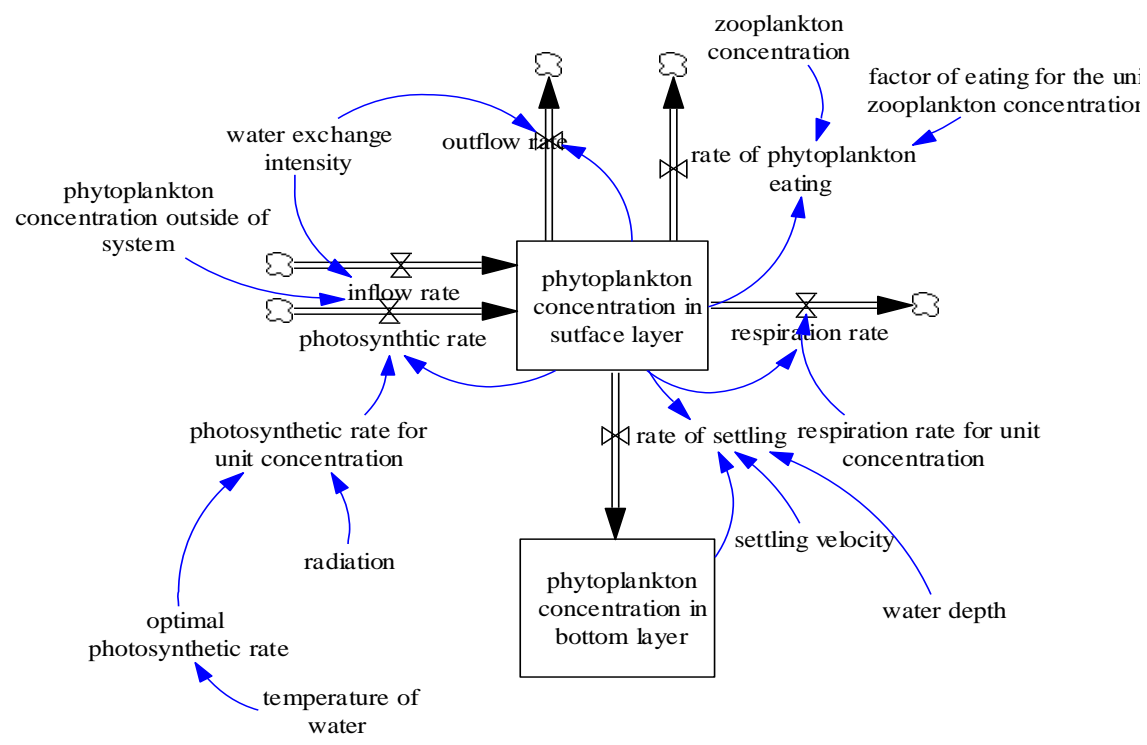

Fig. 1. Model of phytoplankton mass growth in the reservoir (Power Sim).

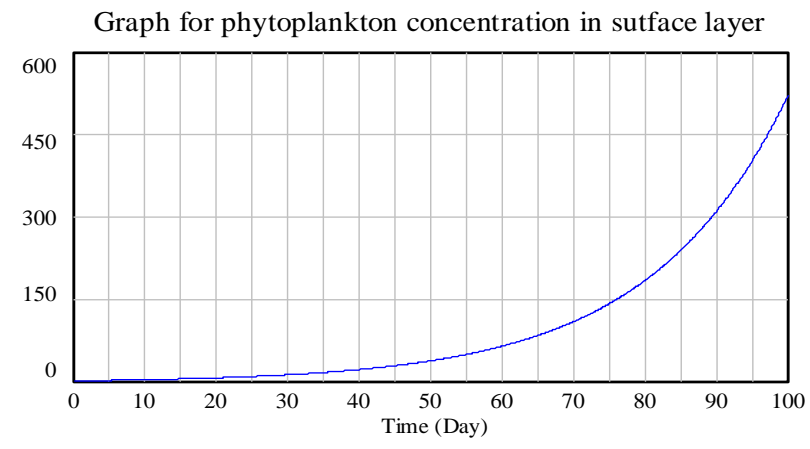

phytoplankton concentration in sutface layer : Current $\mathrm{mga} / \mathrm{m} 3$

Fig. 2. Increase in phytoplankton concentration in the surface layer with poor water exchange.

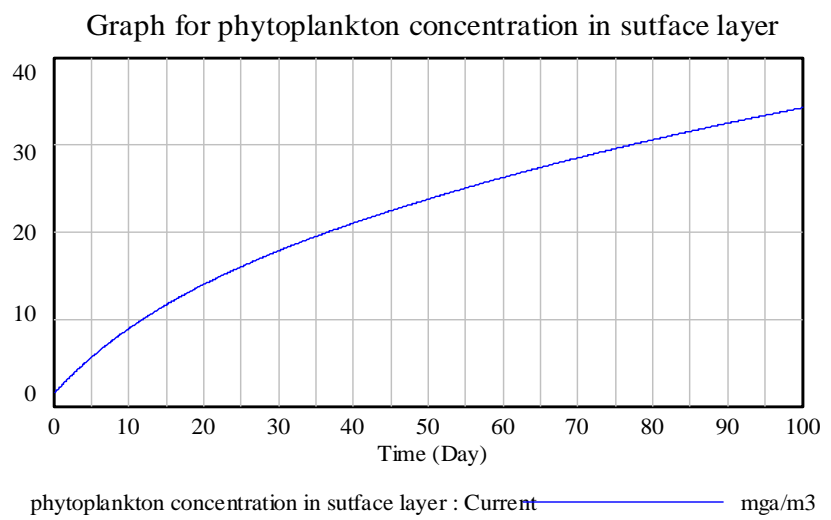

Fig. 3. Simulation of phytoplankton concentration growth in the surface layer during intensive water exchange. 


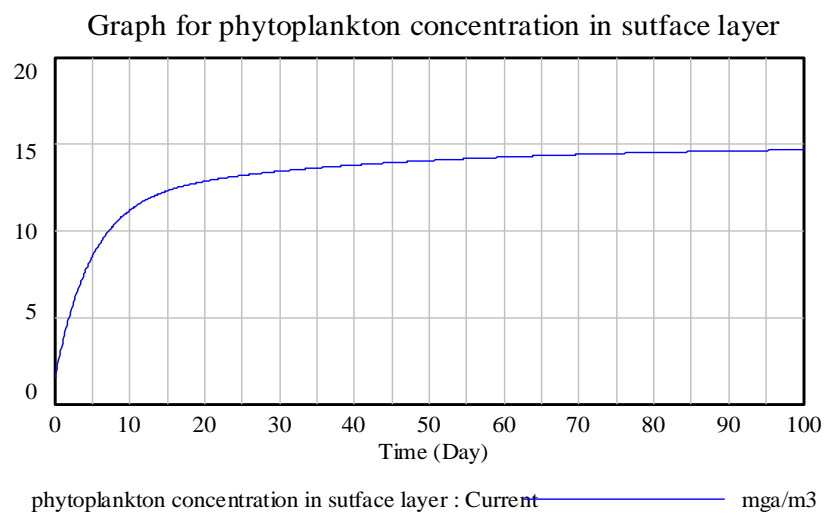

Fig. 4. Simulation of phytoplankton concentration growth in surface layer with more intensive water exchange.

The concentration of phytoplankton increases dramatically and one can expect eutrophication of the water area and destruction of the aquatic ecosystem after about 50-60 days.

Increasing the intensity of water exchange changes the situation. If you increase water exchange, then the growth of phytoplankton becomes stable - in calculations based on the model of the same situation, with a water exchange intensity of 0.1 days- 1 , stabilization occurs after 50-60 days, and with a water exchange intensity of 0.25 days-1, stabilization occurs after 4 days.

\subsection{Water exchange for aquatories near coastal protection structures}

A fundamentally different situation is associated with the modeling of water exchange for the aquatory near the coastal structures. Traditional coastal protection structures, such as, for example, groins, pierces, breakwaters and others, can partially or completely close the coastal area. At the same time, the water exchange of such fenced territories with the main sea area is weaken. Water exchange factors for these areas are wind and currents induced by collapsing waves.

Coastal protection structures are usually located near the coastal line. This is an additional problem for using high-level mathematical models to simulate water exchange. The reason for this is that the circulation of water masses near the shore significantly changes under the influence of various factors: refraction and diffraction of waves, reflection of waves from coastal protective structures, wave breaking, interaction of waves and currents, formation of bursting currents and stagnant zones, etc. However, lower level models can produce satisfactory results despite the complexity of the simulated processes [7-8]. The water exchange scheme for a single groin is shown in Fig. 5.

At the same time, turbulent diffusion in the surge zone is so strong that the applicability region of the 0 -dimensional model can be achieve in a relatively short time. A horizontal turbulent diffusion factor is required to estimate the time scale T. There are different approximations for the horizontal turbulent diffusion factor in the surge zone. 


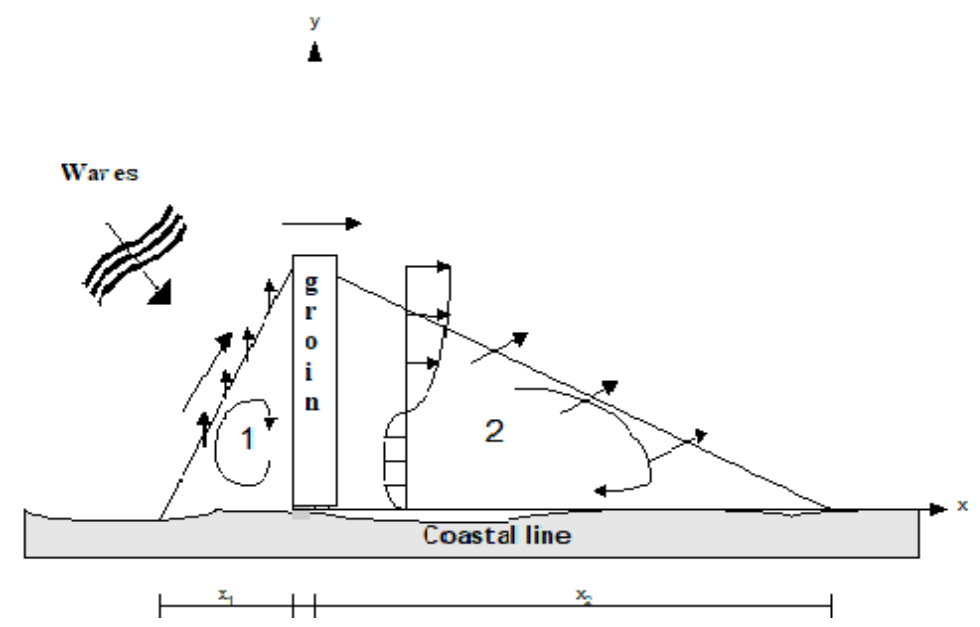

Figure 5. Water exchange for a single groin. Flow diagram.

Let's use one of the known approximation [7-15]:

$$
D=\frac{H_{b} X_{b}}{T}
$$

where: $\mathrm{Hb}, \mathrm{Xb}$ are the wave height along the breaking line and the distance from the breaking line to the shore, respectively, and $\mathrm{T}$ is the wave period. Taking $\mathrm{Xb}=\mathrm{L}$, $\mathrm{Hb}=\mathrm{db}=\mathrm{L} * \operatorname{tg} \alpha, \mathrm{db}-$ depth in the breaking line, $\operatorname{tg} \alpha$, - representative bottom slope in the surfaced zone.

Then the expression for diffusion coefficient can be written as:

$$
D=\frac{L^{2} \tan \alpha}{T}
$$

From (6) gives:

$$
T_{\varepsilon}=\frac{4}{\pi^{2}} \frac{T}{\tan \alpha} \ln \frac{4}{\pi \varepsilon}
$$

or

$$
\frac{T_{\varepsilon}}{T}=\frac{4}{\pi^{2}} \frac{1}{\tan \alpha} \ln \frac{4}{\pi \varepsilon}
$$

The performed analysis suggests that there are no serious limitations on the application of the 0 -dimensional model in this aspect.

An illustration of a 0 -dimensional simulation of water exchange in the field of coastal protection structures and a comparison of the effect of typical coastal protection structures on water exchange is shown in detail in [7-15].

The use of permeable structures can significantly increase water exchange in the protected water area [8-13]. Also, permeability significantly increase water exchange in semi-enclosed areas in the coastal zone with suitable waves, which have an angle to the coastal line.

The use of intermittent coastal defences that are parallel to the coastline is effective in beach restoration projects. With the oblique approach of waves to the shore, the water exchange between the fenced aquatory and the main water area is sufficient. However, if in the complex with these structures the transverse to the coast structures are used, then the intensity of water exchange is significantly reduce. This is especially noticeable with a normal approach of waves to the shore. Thus, such a coastal protection system can lead to a deterioration in the quality of seawater in the protected area and requires special analysis. 
0 -dimensional models of water exchange can be use in studies, including in predicting the quality of coastal waters. In particular, this type of model provides comparative estimates of the effect of various typical coastal protection structures and various combinations thereof on water exchange in protected coastal areas. Assessing the applicability of 0 -dimensional models is an important part of such studies.

\section{Conclusion}

The concept of sustainable development is being actively introduce in coastal regions. Therefore, the importance of the ecological state of coastal regions, primarily focused on recreational and tourist activities, is also growing.

The state of the water resources of the coastal zone plays an important role in the sustainable development of such coastal tourist areas, for which the quality of seawater is crucially.

Analysis of physical factors of water exchange and assessment of the quality of water resources of the coastal zone of the sea, including in closed and semi-enclosed water areas, which are construct in the coastal zone because of coastal protection measures and hydrotechnical construction, was carried out.

It has been shown that water exchange is the most important factor in the management of the quality of marine waters of partially enclosed coastal areas.

The results of the studies made it possible to assess the circulation of coastal marine waters and the change in certain indicators of the quality of water resources, including in the presence of various coastal protection facilities. It was shown that 0 -dimensional models of water exchange could be used in studies, including in predicting the quality of coastal waters.

The obtained results can be use to predict the state of water resources in coastal waters of sea resort.

\section{References}

1. ISO 140042019 Environmental management systems - General guidelines on principles, systems and support techniques http://tic.tsu.ru/www/uploads/smart-section /19_ISO_14000.pdf

2. GOST R ISO 14005-2019 2019 Environmental Management Systems. Guidelines for a flexible approach to the phased implementation of environmental management https://allgosts.ru/13/020/gost_r_iso_14005-2019

3. 2000 The Eco-indicator 992000 A damage oriented method for Life Cycle Impact Assessment. Manual for Designers www.pre-sustainability.com

4. Kantardgi I 2005 The Eco-Indicating of the Black Sea Environmental Damage. Workshop Clean Black Sea Working Group (Varna, Bulgaria: Proceedings Book, Bulgarian Academy of Sciences) p 36

5. Korobko V I 2015 Russian journal of resources, conservation and recycling 2 http://resources.today/PDF/04RRO215

6. 1989 Handbook of Chemistry (St. Petersburg: Hydrometeoisdat) p 391 http://elib.rshu.ru/files_books/pdf/img-224120733.pdf\#1

7. Kantardgi I, Mairanovsky F and Sapova N 1995 Coastal Engineering 26207

8. Gordeeva TB 2002 Development of methods for calculating water exchange for semienclosed water areas of the coastal zone Autoreferat dissertation (MGSU) p 24 
9. Kantardg I 2004 Proc. of Moscow State Civil Engineering University 35

10. I. Kantardgi 2004 Proc. of Moscow State Civil Engineering University 40

11. Kantardgi I G, Yakushev E V and Prokhoda-Shumskikh L V 2007 Review of Applied and Industrial Mathematics 14(2) 306

12. Kantardgi I G, Yakushev E V and Prokhoda-Shumskikh L V 2007 Proc. of the XXII International Coastal Conference "The problems of the control and sustainable development of the sea coastal zone" 240

13. Prokhoda-Shumskikh L, Dreizis Yu and Kantardgi I 2007 Proc. of the 8th Int. Conf. on the Mediterranean Coastal Environment, MEDCOAST 0721207

14. Dreizis Yu I, Prokhoda-Shumskikh L V 2009 Proc. of 9-th International Conference (MEDCOAST 2009) p 863

15. Kantarzhi I G, Maderich V S 2013 Engineering and Construction Journal. St. Petersburg State University 2(37) 75

16. Lukashov E A, Alekhine V E, Poserin S P 2006 Theoretical and applied problems of service 4(21) 18 